ISSN 2782-358X (Print), 2782-3598 (Online)

\title{
m Теория музыки жr
}

Научная статья

УДК 781.41

DOI: $10.33779 / 2782-3598.2021 .4 .007-015$

\section{«Верное наставление в сочинении генерал-баса» Давида Кельнера: о первичном тексте русского перевода}

\author{
Инга Александровна Преснякова \\ Российская академия музыки имени Гнесиных, \\ 2. Москва, Россия, \\ inga.presniakova@gmail.com,https://orcid.org/0000-0003-3257-2225
}

\begin{abstract}
Аннотация. Первый русский перевод европейского руководства по генерал-басу трактата «Treulicher Unterricht im General-Ваß» Давида Кельнера был осуществлён в 1791 году и вышел под названием «Верное наставление в сочинении генерал-баса...». Несмотря на очевидность источника, правомерен вопрос о первичном тексте русской версии, так как до её публикации труд Кельнера выдержал семь немецких изданий, полувековая история которых засвидетельствовала внесение изменений различного характера. Сличение текстов трёх первых изданий $(1732,1737,1743)$ и их сравнение с русскоязычной публикацией позволяют установить первичный текст «Верного наставления». В качестве доказательств автор приводит ряд обнаруженных в немецких изданиях различий (вставок, купюр, деталей нотных примеров), соотнесение которых с русским изданием даёт возможность сделать заключение о первом издании как тексте-первоисточнике. Данный вывод открывает пути для дальнейших исследований перевода «Верного наставления», обусловливая объективность анализа его качества и техники, понимание степени вторжения переводчика в структуру текста. Рассмотрение терминологии «Верного наставления» в контексте становления специального музыкально-теоретического аппарата конца XVIII столетия будет способствовать развитию такой новой ветви современной науки, как историческая лексикология отечественного музыкознания.
\end{abstract}

Ключевые слова: Давид Кельнер, «Верное наставление в сочинении генерал-баса», российская музыкальная теория XVIII века, генерал-бас

Для цитирования: Преснякова И. А. «Верное наставление в сочинении генерал-баса» Давида Кельнера: о первичном тексте русского перевода // Проблемы музыкальной науки / Music Scholarship. 2021. № 4. C. 7-15. DOI: 10.33779/2782-3598.2021.4.007-015.

\footnotetext{
Преснякова И. А.
} 


\title{
orn Theory of Music mo
}

Original article

\section{“Treulicher Unterricht im General-Bass" by David Kelner: about the Primary Text of the Russian Translation}

\author{
Inga A. Presnyakova \\ Russian Gnesins'Academy of Music, Moscow, Russia, \\ inga.presniakova@gmail.com,https://orcid.org/0000-0003-3257-2225
}

\begin{abstract}
The first translation into Russian of the European manual textbook on figured bass, David Kelner's “Treulicher Unterricht im General-Baß” was made in 1791 and came out under the title of "Vernoe nastavlenie v sochinenii general-basa..." ["Accurate Instruction in Composition with Figured Bass..."]. Despite the apparent character of the source, there remained the appropriate question about the primary text for the Russian, since prior to the latter's publication, Kelner's work had undergone seven German publications, the half-century long history of which testified to bringing in changes of various types. A collation of the texts of the first three editions $(1732,1737$, 1743) and the comparison of all of them with the publication in Russian has made it possible to establish the primary text of the "Accurate Instruction." The author cites as his proof for this decision a certain number of discrepancies discovered in the German editions (insertions, abridgements, details of musical examples, etc.) the correlation of which with the Russian edition makes it possible to arrive at the conclusion of the first edition being the primary text for the translation. This conclusion discloses the path for further research of the translation of the "Accurate Instruction," stipulating the objectivity of the analysis of its quality and technique and the understanding of the level of interference into the text's structure on the part of the translator. Close examination of the terminology of the "Accurate Instruction" in the context of the formation of the special music theory apparatus of the end of the 18th century will be conducive to the development of such a new branch of contemporary scholarship as the historical lexicology of Russian musicology.

Keywords: David Kelner, "Treulicher Unterricht im General-Bass," 18th century Russian music theory, figured bass

For citation: Presnyakova I. A. "Treulicher Unterricht im General-Bass" by David Kelner: about the Primary Text of the Russian Translation. Problemy muzykal'noj nauki / Music Scholarship. 2021. No. 4, pp. 7-15. (In Russ.). DOI: 10.33779/2782-3598.2021.4.007-015.
\end{abstract}

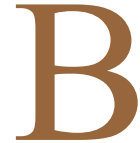

истории отечественной музыкальной теории «Верное наставление в сочинении генерал-баса» Давида Кельнера $(1791)^{1}$ имеет особый статус: это первое специализированное руководство по генерал-басу, изданное на русском языке, и первый опыт перевода зарубежного издания подобного типа.
Его появление представляется особенно примечательным в отношении двух актуальных для состояния российской теории музыки конца XVIII столетия процессов. Первый из них заключается во внедрении европейской музыкальной науки в отечественное культурное пространство: посредством труда Кельнера, который 
сам автор характеризует как компендиум, транслируются не только его собственные теоретические и педагогические установки, но также идеи повлиявших на руководство и упоминаемых на его страницах немецких и французских авторов И. Д. Хайнихена, И. Маттезона, Ш. Массона, С. Броссара, Ж.-Ф. Рамо. Вторым из названных процессов является формирование русскоязычного музыкально-теоретического лексикона: данный перевод ярко демонстрирует особенности его начального этапа. Исследование, направленное на изучение данных процессов и специфики их отражения в «Верном наставлении», вряд ли возможно без обращения к тексту первоисточника. Однако проблема установления оригинала до сих пор не была поставлена даже в тех немногочисленных научных изысканиях, что прямо или косвенно связаны с руководством Кельнера. В работах современных исследователей расставлены иные акценты: К. Спарр [1] реконструирует жизненный путь музыканта; А. В. Бояркина [2; 3; 4; 5] специализируется на лингвистической проблематике перевода немецкоязычных руководств; Л. В. Кириллина [6] анализирует русские версии музыкальных трактатов XVIII столетия; автор данной статьи в других публикациях описывает музыкально-теоретическую терминолексику в аспекте её исторического становления [7; 8; 9].

Вопрос о поиске первичного текста «Верного наставления» не так курьёзен, как может представляться на первый взгляд. Казалось бы, ответ очевиден и давно известен - это трактат Давида Кельнера (David Kellner) «Treulicher Unterricht im General-Baß»: титул русского издания указывает на него, демонстрируя читателю фамилию автора («сочинённое господином Д. Келнером»), название (хотя и несколько трансформированное - «Верное наставление в сочинении генерал-баса») и указание на язык первоисточника («Переведённое с немецикого на российской H. Зубриловым»). Наличие этих данных - хорошая опора для читателя той эпохи и для современного исследователя, поскольку подобного рода информация в изданиях XVIII - начала XIX века содержалась далеко не всегда: фигура автора или переводчика могла быть скрыта за криптонимом (заметим, что именно так обстояло дело с первым и вторым немецкими изданиями «Treulicher Unterricht im General-Baß», где были указаны только инициалы Кельнера - D. К.). Случалось, что русскоязычные версии европейских руководств выглядели как «анонимные» (что произошло, как известно, при публикации фрагмента «Краткого показания игры на клавикордах» Д. Г. Тюрка в «Карманной книжке для любителей музыки на 1796 год»). И всё же данных титула «Верного наставления» недостаточно для определения первичного текста по причине того, что с момента публикации «Treulicher Unterricht im General-Baß» в 1732 году до выхода в свет его русского перевода, осуществлённого спустя почти 60 лет, труд Кельнера был семикратно (!) переиздан в Германии, причём в переиздания (прижизненные и посмертные) вносились изменения. Этот факт и образует проблему первоисточника, указания на который переводная версия не содержит. Более того, забегая вперёд, скажем, что некоторые детали отечественного издания скорее могут направить исследователя на ложный след, чем приблизить к разгадке.

Какие гипотезы относительно первоисточника позволяет выдвинуть русскоязычное издание? Во-первых, указание фамилии автора на титуле «Верного наставления» даёт основания полагать, что в основе перевода могло лежать одно из 
изданий, на обложках которых она значилась в полном виде, - то есть начиная с третьего. Во-вторых, не лишено логики предположение, что в качестве первичного текста было использовано одно из тех изданий, что вышли в свет незадолго до появления русского перевода - например, шестое (1782) или седьмое (1787). Вескую причину для выбора более ранней версии руководства найти достаточно сложно: вряд ли российский издатель конца XVIII столетия надеялся привлечь внимание читателей трактатом более чем полувековой давности. Например, И. Д. Герстенберг, печатая в «Карманной книжке на 1796 год» вступление из клавирного руководства Тюрка, обосновывает причину публикации тем, что «До ныне нет в сем роде хорошей на Русском языке книги. Лелейна клавикордная школа стара» ${ }^{2}-$ при том, что русский её перевод вышел в свет в 1773 году.

И всё же обращение к немецким первоисточникам трактата Кельнера позволяет с уверенностью утверждать, что русский перевод был выполнен с первого издания. «Возраст» же оригинала, возможно, был намеренно скрыт: в завершении предисловия (Der Verleger an den geneigten Leser) немецкого руководства стоит дата 2 мая 1732 года, которая изъята из русского «Предуведомления от издателя», хотя весь остальной текст раздела передан без купюр. При этом в отечественном издании дешифруется криптоним автора, что свидетельствует, вероятно, об информированности издателя или переводчика о наличии более поздних версий трактата и его востребованности в музыкальной среде.

Какие сведения подтверждают факт европейского признания труда Кельнера? В первую очередь, множественные немецкие переиздания и публикации на швед- ском (1739) и датском $(1741,1751)$ языках.

Вместе с тем, как указывает К. Спарр [1], первый публичный отклик на труд Кельнера, появившийся на страницах «Nieder-Sächsische Nachrichten von Gelehrten neuen Sachen» 26 июня 1732 года, был резко отрицательным, а за саркастичным и язвительным тоном анонимного автора скрывался авторитетный голос И. Маттезона. Однако его мнение не получило поддержки: анонсированное в «Nieder-Sächsische Nachrichten von Gelehrten neuen Sachen» 10 апреля 1732 года первое издание тиражом 2000 экземпляров было раскуплено за год, на что указывает Г. Ф. Телеман в предисловии ко второму изданию 1737 года ${ }^{3}$. Как и многие другие выдающиеся представители музыкальной культуры того времени, он высоко оценил труд Кельнера. В исследовании К. Спарра приводятся примеры, демонстрирующие статус трактата Кельнера среди европейских музыкантов.

Вот некоторые из них. Лоренц Кристоф Мицлер, видный немецкий теоретик, основатель «Общества музыкальных наук», издатель журнала «Музыкальная библиотека» («Neu eröffnete musikalische Bibliothek») в одном из номеров за 1736 год (1 том) помещает краткое изложениепервого издания и рекомендует книгу Кельнера для начинающих, предлагая «OrganistenProbe» Маттезона для дальнейшего изучения. Якоб Адлунг несколько раз упоминает Кельнера в своём руководстве «Anleitung zu der musikalischen Gelahrtheit» (1758). Кристоф Готлиб Шретер положительно отзывается о «Treulicher Unterricht» в учебнике «Deutliche Anweisung zum General-Bass» (1772). Кроме того, разные издания «Treulicher Unterricht» Кельнера обнаружены в библиотеках известных музыкантов - «отца» шведской музыки Йохана Гельмиха Романа, немецкого 
органиста и музыкального теоретика Даниэля Готтлоба Тюрка, венского классика Йозефа Гайдна. Экземпляр, принадлежавший последнему, испещрён пометками, сделанными рукой композитора. Данные факты свидетельствуют о том, что руководство Кельнера, хотя и было предназначено для начального обучения, использовалось и профессиональными музыкантами.

Отметим также и то, что ссылка на труд Кельнера присутствует в оригинале «Клавикордной школы» Лёлейна и в её русском переводе 4 . Возможно, именно этот момент стал ключевым фактором, обусловившим выбор «Treulicher Unterricht im General-Baß» в качестве первого опыта перевода специализированного руководства по генерал-басу. Перевод же был выполнен с первого немецкого издания.

Уверенное утверждение о первичном тексте «Верного наставления» основано на сличении текстов доступных нам первого, второго, третьего изданий и их сравнении с русской публикацией. Ограничение материала хронологически первыми изданиями поначалу было оправдано их прижизненной датировкой; впоследствии же, по установлении первого издания как первичного текста «Верного наставления», необходимость в привлечении более поздних изданий отпала.

Анализ немецких изданий 1732, 1737 и 1743 годов показал, что их отличия не имеют принципиального характера для структуры и содержания целого: основной массив текста первого издания сохраняется во втором и третьем. Наиболее заметны расхождения в отношении вспомогательных разделов. По сравнению с первым, во втором издании добавлено предисловие («Vor Rede») Г. Ф. Телемана и послесловие от автора («Noch ein Wort»), появившееся как реакция на критику Маттезона в «Nieder-Sächsische Nachrichten». В издании 1743 года купировано послесловие, а вступительное слово Телемана было заменено на предисловие Даниэля Соландера, профессора Университета Уппсалы (как значится в тексте, Daniel Solander. Prof. Jur. Patr. \& Rom. Upsal), первоначально появившееся в шведском издании 1739 года. Русское издание не содержит ни одного из названных разделов.

Авторские коррективы внутритекстового характера обнаруживаются не столь явно. Однако в ракурсе нашей проблемы поиск этих изменений становится важной задачей, решение которой даёт ответ на вопрос о первичном тексте «Верного наставления».

Различия первых трёх изданий имеют характер внутренних текстовых корректив, добавлений, купюр, вставки нотных примеров. Так, второе издание на обложке обозначено как расширенное («Zweite und vermehrte Auflage»). К. Спарр отмечает, что в нём изменений и добавлений по сравнению с первым изданием немного [1, p. 49]. Однако нами обнаружено более тридцати (!) авторских правок различного характера - от добавления/купирования единичных слов и словосочетаний до расширений, объём которых превышает полторы страницы, кроме того, изменения коснулись нотных примеров, коррекции структуры таблиц и их наполнения. На титуле третьего издания, в отличие от второго, нет информации о его соотношении с предыдущим. Этот факт позволяет предположить, что издание 1743 года могло быть стереотипным. Однако сравнение второго и третьего изданий выявило более десяти расхождений различного плана.

Приведём лишь неполный ряд отличий немецких изданий и соотнесём их с русским переводом. 
По сравнению с первым изданием 1732 года, в издании 1737 года расширен объём некоторых глав.

В главе I пункт II дополнен незначительным пояснением («Diese natürliche Tabelle ist insonderheit für Kinder und andere annoch rohe Incipienten, die nur fürs erste so crasse das Intervallum einer Tertie sollen kennen lernen» ${ }^{5}$ ), а пункт XXIV - уточнением о местоположении речитатива («und werden zwischen die Arien gesetz» $\left.{ }^{6}\right)$. Обе вставки сохранены в тексте третьего издания, но в русском издании соответствующих им предложений нет.

II глава («Vom Gebrauch der Signaturen») в первом издании содержала 28 параграфов, во втором их количество возросло до 34. В соответствии с этим изменилось и количество строк в завершающей главу таблице сигнатур: в первом издании их 23, во втором - 29. Русское издание следует первому.

В разделе «Erklärung des Aufsteigens des Dur-Thone» главы III второго издания появляется нотный пример. В русском издании он не представлен.

B VI главе укрупняется абзац, посвящённый малой терции ${ }^{7}$, после которого предполагается наличие нового нотного примера, так и не попавшего в основной текст и нашедшего место поначалу лишь в списке опечаток, а затем в третьем издании $^{8}$. В VII главе в несколько раз объёмнее становится раздел, посвящённый увеличенной квинте; в нём также добавлен нотный пример. Объём данных разделов в отечественном руководстве соответствует первому изданию.

Во втором издании автор посчитал необходимым изменить порядок столбцов в таблицах главы VII («Tabella locationis Dissonantiarum in den Dur-Thönen; Tabella locationis Dissonantiarum in den MollThönen ${ }^{9}$ ). В русском варианте структура таблиц идентична таблицам первого издания.

В текстах глав третьего издания, по сравнению со вторым, обнаружены краткие вставки (одно слово, одно предложение), расширения за счёт новых одного или двух абзацев, а также неоднократные купюры. Добавление материала повлекло за собой включение новых нотных примеров (глава V), а обнаружение неточностей в музыкальном примере предыдущего издания - его корректировку ${ }^{10}$. Эти изменения не представлены в русском переводе.

Укажем также на некоторые детали нотных примеров, которые дополнят ряд доказательств в пользу первого издания как первичного текста русского перевода.

В такте 3 нотного примера пункта XIV главы I нота $h$ в партии нижнего голоса имеет разное октавное положение: в первом издании она располагается в малой октаве ${ }^{11}$, во втором и третьем в большой ${ }^{12}$. Русская публикация соответствует первому изданию.

Первый нотный пример главы II coстоит из единственной ноты в басовом ключе: в первом ${ }^{13}$ и третьем ${ }^{14}$ изданиях $-e$, во втором $-c^{15}$. В русском издании пример аналогичен первому и третьему изданиям.

В такте 6 третьего нотного примера главы VI в первом, третьем и русском изданиях помещена квинта $h$ - fis; во втором издании присутствует только fis.

Ряд обнаруженных отличий можно продолжить, но приведённых выше доказательств достаточно для того, чтобы уверенно сделать вывод: первичным текстом «Верного наставления» является первое издание «Treulicher Unterricht im General-Baß».

Какие исследовательские перспективы открывает уверенность в обнару- 
жении оригинального текста? В первую очередь те, что связаны с объективностью анализа качества и техники перевода. Полученная информация позволяет установить, насколько точно в русской версии была сохранена структура оригинала, были ли сделаны переводчиком купюры или вставки, посредством какого языка в русский лексикон входи- ли те или иные музыкальные термины. Рассмотрение терминологии «Верного наставления» в контексте становления специального музыкально-теоретического аппарата конца XVIII столетия будет способствовать развитию такой новой ветви современной науки, как историческая лексикология отечественного музыкознания.

\section{m Примечания жо}

1 Кельнер Д. Верное наставление в сочинении генерал-баса. М.: Унив. тип., 1791. 98 с.

2 Карманная книжка для любителей музыки на 1796 год / Иждивением книгопродав. И. Д. Герстенберга и тов. СПб.: Тип. И. К. Шнора, [1795]. С. 20.

3 Kellner D. Treulicher Unterricht im General-Baß. Zweite und vermehrte Auflage. Hamburg, 1737. $98 \mathrm{~S}$.

4 Лёлейн Г.С. Клавикордная школа. М.: Императорский Московский ун-т, 1773-1774. $188 \mathrm{c}$.

5 Kellner D. ... Zweite und vermehrte Auflage. Hamburg, 1737, S. 9.

6 Ibid., S. 19.

7 Ibid., S. 65.

8 Kellner D. Treulicher Unterricht im General-Baß. Dritte Auflage. Hamburg, 1743, S. 65.

9 Kellner D. Treulicher Unterricht im General-Baß. Hamburg, 1732, S. 91-92; Kellner D. ... Zweite und vermehrte Auflage. Hamburg, 1737, S. 96-97.

${ }^{10}$ Kellner D. ... Zweite und vermehrte Auflage. Hamburg, 1737, S. 76-77; Kellner D. ... Dritte Auflage. Hamburg, 1743, S. 77.

${ }^{11}$ Kellner D. Treulicher Unterricht im General-Baß. Hamburg, 1732, S. 12.

${ }^{12}$ Ibid., S. 12; Kellner D. ... Zweite und vermehrte Auflage. Hamburg, 1737, S. 12.

${ }^{13}$ Kellner D. ... Zweite und vermehrte Auflage. Hamburg, 1737, S. 21.

${ }^{14}$ Kellner D. ... Dritte Auflage. Hamburg, 1743, S. 21.

${ }^{15}$ Kellner D. ... Zweite und vermehrte Auflage. Hamburg, 1737, S. 21.

${ }^{16}$ Кельнер Д. Верное наставление в сочинении генерал-баса. М., 1791. С. 26.

\section{m Список источников мо}

1. Sparr K. David Kellner. A Biographical Survey. Stockholm, Sweden, 1997. 71 p.

2. Бояркина А. В. Терминология в первых русских переводах музыкальных трактатов (на примере «Клавикордной школы» Г. С. Лёлейна) // Немецкая филология в СанктПетербургском государственном университете / под ред. С.Т. Нефёдова, И. Е. Езан. СПб., 2021. С. 260-282.

3. Бояркина А. В. Немецкие музыкальные термины: некоторые особенности функционирования в эпистолярном тексте и проблемы перевода // Термины, понятия и 
категории в музыковедении: тезисы докладов IV Междунар. конгресса Общества теории музыки, Казань, 2-5 октября 2019 г. / ред. Е. В. Порфирьева, В. В. Сепешвари. Казань, 2019. С. $83-84$.

4. Бояркина А. В. Переводы трудов Гуго Римана на русский язык // Журнал Общества теории музыки. 2017. № 2 (18). С. 41-48. URL:

http://journal-otmroo.ru/sites/journal-otmroo.ru/files/2017_2\%2818\%29_3_Boyarkina_trans_riemann.pdf (дата обращения: 30.09.2021).

5. Бояркина А. В. О переводе старинных музыкально-теоретических текстов (на примере трактатов по генерал-басу) // Вестник Академии русского балета им. А. Я. Вагановой. 2015. № 4 (39). С. 189-194.

6. Кириллина Л. В. Русские переводы немецких музыкальных трактатов XVIII века // Русские и немцы в XVIII веке: встреча двух культур / отв. ред. С. Я. Карп. М., 2000. С. 84-91.

7. Преснякова И. А. Российская музыкально-лексикографическая практика XVIII века: к проблеме изучения // Музыкальная наука в контексте культуры: сб. по материалам Междунар. науч. конф., 30 октября - 2 ноября 2018 года / ред. Т. И. Науменко, Е. С. Дерунец, Ю. Н. Пантелеева, И. А. Преснякова; Рос. академия музыки им. Гнесиных. М., 2018. С. 120-130.

8. Преснякова И. А. «Практическое руководство к сочинению музыки» И. Л. Фукса (1830) в переводах М. Резвого и Г. Арнольда: К проблеме становления русскоязычной музыкальнотеоретической терминологии в первой половине XIX столетия // Термины, понятия и категории в музыковедении: тезисы докладов IV Междунар. конгресса Общества теории музыки, Казань, 2-5 октября 2019 г. / ред. Е. В. Порфирьева, В. В. Сепешвари. Казань, 2019. C. $81-82$.

9. Преснякова И. А. Музыкальная лексика в толковых словарях конца XVIII - первой половины XIX века // Научные школы в музыковедении XXI века: к 125-летию учебных заведений имени Гнесиных: материалы Междунар. науч. онлайн-конф. 24-27 ноября 2020 года / ред. Т.И. Науменко; Российская академия музыки имени Гнесиных. М., 2020. С. 317-324. URL: https://gnesin-academy.ru/wp-content/documents/nauka/Nauchnie_shkoli_v_musikovedenii_Sbornik_statey_2020.pdf (дата обращения: 30.09.2021).

Информация об авторе:

И. А. Преснякова - кандидат искусствоведения, доцент кафедры теории музыки.

\section{meferences mo}

1. Sparr K. David Kellner. A Biographical Survey. Stockholm, Sweden, 1997. 71 p.

2. Boyarkina A. V. Terminologiya v pervykh russkikh perevodakh muzykal'nykh traktatov (na primere «Klavikordnoy shkoly» G. S. Leleyna) [Terminology in the First Russian Translations of Musical Treatises (on the Example of the "Clavichord School" by Georg Simon Löhlein)]. Nemetskaya filologiya $v$ Sankt-Peterburgskom gosudarstvennom universitete [German Philology at the St. Petersburg State University]. Ed. by S. T. Nefedova, I. E. Ezan. St. Pretersburg, 2021, pp. 260-282. (In Russ.).

3. Boyarkina A. V. Nemetskie muzykal'nye terminy: nekotorye osobennosti funktsionirovaniya $\mathrm{v}$ epistolyarnom tekste i problemy perevoda [German Musical Terminology: Certain Features of Functioning in the Epistolary Text and Issues of Translation]. Terminy, ponyatiya i kategorii $v$ muzykovedenii: tezisy dokladov IV Mezhdunar. kongressa Obshchestva teorii muzyki, Kazan', 2-5 oktyabrya $2019 \mathrm{~g}$. [Terms, Concepts and Categories in Musicology: Abstracts of the 4th 
International Congress of the Russian Society for Music Theory, Kazan, 2-5 October 2019]. Edited by E. V. Porfirieva, V. V. Sepeshvari. Kazan, 2019, pp. 83-84. (In Russ.).

4. Boyarkina A. V. Perevody trudov Gugo Rimana na russkiy yazyk [Translations of Hugo Riemann's Works into Russian]. Zhurnal Obshchestva teorii muzyki [The Journal of the Society for Music Theory]. 2017. No. 2 (18), pp. 41-48. URL: http://journal-otmroo.ru/sites/journalotmroo.ru/files/2017_2\%2818\%29_3_Boyarkina_trans_riemann.pdf(30.09.2021). (In Russ.).

5. Boyarkina A. V. O perevode starinnykh muzykal'no-teoreticheskikh tekstov (na primere traktatov po general-basu) [About the Translation of Early Music Theory Texts (on the Example of Treatises on Thoroughbass)]. Vestnik Akademii russkogo baleta im. A. Ya. Vaganovoy [Bulletin of the Vaganova Ballet Academy]. 2015. No. 4 (39), pp. 189-194. (In Russ.).

6. Kirillina L. V. Russkie perevody nemetskikh muzykal'nykh traktatov XVIII veka [Russian Translations of 18th Century German Musical Treatises]. Russkie i nemtsy v XVIII veke: vstrecha dvukh kul'tur [Russians and Germans in the 18th Century: The Meeting of Two Cultures]. Ed. by S. Ya. Karp. Moscow, 2000, pp. 84-91. (In Russ.).

7. Presnyakova I. A. Rossiyskaya muzykal'no-leksikograficheskaya praktika XVIII veka: k probleme izucheniya [Russian Musical and Lexicographic Practice from the 18th Century: Towards the Issue of Research]. Muzykal'naya nauka v kontekste kul'tury: sb. po materialam Mezhdunar. nauch. konf., 30 oktyabrya - 2 noyabrya 2018 goda [Music Scholarship in the Context of Culture: Proceedings of the International Academic Conference, 30 October - 2 November 2018]. Edited by T. I. Naumenko, E. S. Derunets, Yu. N. Panteleyeva, I. A. Presnyakova. Russian Gnesins' Academy of Music. Moscow, 2018, pp. 120-130. (In Russ.).

8. Presnyakova I. A. «Prakticheskoe rukovodstvo k sochineniyu muzyki» I. L. Fuksa (1830) v perevodakh M. Rezvogo i G. Arnol'da: K probleme stanovleniya russkoyazychnoy muzykal'noteoreticheskoy terminologii v pervoy polovine XIX stoletiya ["A Practical Guide to Composing Music" by Johann Leopold Fuchs (1830) translated by M. Rezvyy and G. Arnold: Concerning the Issue of the Formation of Music Theory Terminology in Russian in the First Half of the 19th Century]. Terminy, ponyatiya i kategorii v muzykovedenii: tezisy dokladov IV Mezhdunar. kongressa Obshchestva teorii muzyki, Kazan', 2-5 oktyabrya 2019 g. [Terms, Concepts and Categories in Musicology: Abstracts of the 4th International Congress of the Russian Society for Music Theory, Kazan, 2-5 October 2019]. Edited by E. V. Porfirieva, V. V. Sepeshvari. Kazan, 2019, pp. 81-82. (In Russ.).

9. Presnyakova I. A. Muzykal'naya leksika v tolkovykh slovaryakh kontsa XVIII - pervoy poloviny XIX veka [Musical Vocabulary in the Explanatory Dictionaries from the Late 18th and the First Half of the 19th Centuries]. Nauchnye shkoly v muzykovedenii XXI veka: k 125-letiyu uchebnykh zavedeniy imeni Gnesinykh: materialy Mezhdunar. nauch. onlayn-konf. 24-27 noyabrya 2020 goda [Academic Schools in Musicology in the 21st Century: Towards the 125th Anniversary of the Gnesin Educational Institutions: Proceedings of the International Academic Online Conference]. Edited by T. I. Naumenko. Russian Gnesins' Academy of Music. Moscow, 2020, pp. 317-324. (In Russ.). URL: https://gnesin-academy.ru/wpcontent/documents/nauka/Nauchnie_shkoli_v_musikovedenii_Sbornik_statey_2020.pdf(30.09.2021).

Information about the author:

Inga A. Presnyakova - Ph.D. (Arts), Associate Professor at the Department of Music Theory.

Поступила в редакцию / Received: 19.10.2021

Одобрена после рецензирования / Revised: 11.11.2021

Принята к публикации / Accepted: 12.11.2021

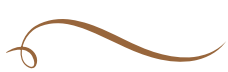

